\title{
Testing the effectiveness of Community-Based Continuous Training Project on Improving the Domains of Birth Preparedness and Complication Readiness Intention Among Expecting Couples in Rural Settings of Rukwa Tanzania, A Controlled Quasi Experimental Study
}

Fabiola Vincent Moshi ( $\sim$ fabiola.moshi@gmail.com ) University of Dodoma

\section{Research Article}

Keywords: Birth preparedness, Attitude, Perceived Subjective Norms, Perceived Behavior Control, pregnant women, male partners

Posted Date: October 21st, 2021

DOI: https://doi.org/10.21203/rs.3.rs-952595/v1

License: (c) (i) This work is licensed under a Creative Commons Attribution 4.0 International License. Read Full License 


\section{Abstract}

Background: According to theory of planned behavior, the intention to engage into a behavior predicts the behavior to occur. The intention to engage into a behavior is influenced by three domains which are the attitude towards the behavior, the perceived subjective norms and the perceived behavior control. The study aimed at testing the effectiveness of a Community Based Continuous training (CBCT) intervention on improving the three domains of Birth Preparedness and Complication Readiness (BPCR) intention.

Method: The quasi-experimental study design with control was done from June 2017 until March 2018. A multi-stage sampling technique was used to obtain 561 couples. Pre-test and end-line information were collected using semi-structured questionnaires developed using theory of planned behavior. The effectiveness of the intervention on improving domains of BPCR intention was assessed by using both independent t-test and pared t-test.

Results: In comparison between groups at posttest assessment, there was a significant increase in mean scores only on perceived subjective norms in the intervention group if compared to the control group among pregnant women. Among male partners, none of the domain showed a significant difference between the intervention group and control group. In the comparison within groups, mean scores in all three domains had significant increase at posttest in both groups among male partners while among pregnant women the significant increase in the three domains were only among pregnant women in the intervention group.

The predictor of change on attitudes and subjective norms mean scores were only the intervention $\beta=0.065, p<0.05$ and $\beta=0.112, p=0.001$ respectively. Predictors of change in perceived behavior control mean scores towards birth preparedness were level of education (secondary school, $\beta=0.066, p<0.05$ ), age at marriage (more than 24 years, $\beta=0.069, p<0.05$ ) and ethnic group (others, $\beta=-0.067, p<0.05$ ).

Conclusion: The improvement brought by the intervention indicates that the intervention has the potential to significantly change the attitude and subjective norms domains of BPCR intention. The study recommends the $\mathrm{CBCT}$ intervention to be used in rural community to improve attitude and perceived subjective norms of BPCR intention.

\section{Background}

BPCR is a strategy that encourages pregnant women, their families, and communities to effectively plan for births and be ready for emergencies if they occur [1]. The strategy empowers them with knowledge about danger signs (during pregnancy, labor and childbirth, post-delivery and neonatal period), awareness on the antenatal routine and services offered and to prepare a birth plan and ready for emergency.

BPCR strategy has a potential to eliminate the three delays (delay to make decision to seek care, delay to reach health facility and delay to receive maternal care services in the health facility) to access maternal health services [2]. The first delay (delay to make decision to seek maternal care) is mostly contributed by 
poor knowledge on danger signs [3]. When these signs occur, the decision to seek care is delayed due to lack of correct interpretation of the danger sign. Some they wrongly interpret the signs as needing some rituals, which in turn leads to delay the right decision [4]. Previous studies have identified several barriers towards eradication of first delay such as pregnancy at younger age, ignorance, poverty, unemployment, poor health service utilization, a lower level of assertiveness among women, poor knowledge about obstetric danger signs, and cultural beliefs[5].

Similarly, the second delay (delay to reach the health facilities) also contribute to delay in accessing maternal health services. Rural settings in developing countries have poor roads, some of which are seasonal roads and unreliable mode of transport which are the key barriers towards timely accesses to maternal health services [5]. Preparation for birth and anticipated emergencies has the ability to reduce the second delay. It is a routine for every pregnant woman and her family to develop and implement a birth plan. The birth plan has the following item; saving money for emergency readiness, arrange for a means of transport to facilitate timely reach to health facility during labor or emergency, identify a skilled birth attendant, prepare items which will be used during childbirth such as; warm clothes to cover the baby, pads, a container for dirty clothes, a pair of glove, a razor blade, a mackintosh, identify a female relative to accompany the couple to the health facility, Identify a blood donner and identify a relative who will stay with other siblings during childbirth[6]. The third delay (delay to access care upon arrival) is the delay which occur in health facility. This delay is mostly contributed by limited resources, both human and non-human resources. It can be contributed by lack of good referral system.

Evidence has shown that BPCR strategy has the potential of minimizing the three delays to access maternal health services and hence reduction of maternal and neonatal deaths[7]. It is a key component of safe motherhood which can promote care seeking behavior and timely utilization of health facility delivery service[8]. Despite of the well-established prospective of BPCR strategy on facilitating timely access to maternal services, the uptake of the practice is surprisingly low in developing countries including Tanzania[8-10]. One wonders why such majority of families are not prepared for child birth and its unanticipated complications in a situation with poor infrastructures and unreliable transport. The possible explanation could be the low risk perception towards pregnancy and childbirth as evidenced by a qualitative study done in Sumbawanga rural community among parents who decided to have home childbirth assisted by unskilled birth attendants[4]. Another possible reason could be the belief that birth outcome is pre-determined by a supernatural power in such that cannot be changed by preparations or health facility birth[4].

Low male involvement in BPCR in developing countries has been cited as one of the barriers towards BPCR $[11,12]$. Unlike the global north, low male involvement in BPCR in the global south is entrenched in the structural setups of the health facilities and culture beliefs[13]. Health facilities setups and the arrangement of the maternal health services excluded male partners in such a way that male partners are less informed on BPCR[14]. In addition, male partners perceived the role of maternal services utilization is the responsibility of women. Their role is to provide financial support. It is now recognized that reaching male partners directly to maternal services utilization is a corner stone towards improving BPCR[15]. 
Theory of planned behavior postulate that intention to engage into a behavior predicts the occurrence of the behavior[16]. The intention to engage into a behavior is shaped by three domains, the attitude towards the behavior, the perceived subjective norms and the perceived behavior control[16]. Attitude towards the behavior is influenced by the belief about the behavior and the evaluation of the behavior outcome. The perceived subjective norms domain is influenced by the normative beliefs and motivation to comply to the behavior. This is the perception on whether the important others approve for one engaging to the behavior. The perceived behavior control domain is influenced by the control belief one has about the behavior and the perceived power to engage into the behavior.

Community based continuous training intervention was designed using theory of planned behavior to improve the three domains of BPCR intention. Little was known on the effectiveness of the intervention on improving the three domains of BPCR intention.

\section{Methods}

\section{Study design and setting}

The study used a quasi-experimental study design consisted of a pre- and post-intervention assessment of two non-equivalent groups; an intervention group and a control group. The study was conducted in Rukwa Region in the Southern Highlands of Tanzania. Rukwa Region[14,17].

\section{Study population}

Expecting couples in Rukwa Region with gestation age $\leq 24$ weeks at the time of study. Study population was selected for training in this gestational age range in order to allow enough time to observe the required indicators on domains of birth preparedness.

\section{Sample size calculation and sampling technique}

\section{Sample size calculation}

The sample size for couples involved in the study, was calculated by using the following formula [18]

$$
\mathrm{n}=\{\mathrm{Z} \alpha \sqrt{ }[\pi \mathrm{o}(1-\pi \mathrm{o})]+2 \beta \sqrt{ }[\pi 1(1-\pi 1)]\}^{2}
$$

$$
(\pi 1-\pi \mathrm{o})^{2}
$$


Where:

$\mathrm{n}=$ minimum sample size

$\mathrm{Za}=$ Standard normal deviation (1.96) at 95\% confidence level for this study

$\mathrm{b}=$ standard normal deviate (0.84) with a power of demonstrating a statistically significant difference before and after the intervention between the two groups at $90 \%$

$\Pi \circ=$ Proportion at pre- intervention (Use of skilled delivery in Rukwa region 65\%)

$\Pi 1=$ proportion after intervention (Proportion of families which will access skilled birth attendant 75\%)

$$
\mathrm{n}=\left\{1.96 \sqrt{ }[0.65(1-0.65]+0.84 \sqrt{ }[0.75(1-0.75)]\}^{2}\right.
$$

$$
(0.75-0.65)^{2}
$$

$$
\mathrm{n}=169 \text { couples }+10 \%=187
$$

The required sample size in the intervention group $=187$ couples

Intervention: control ratio $=1: 2$ (using age groups in five years and parity) which aimed at increasing comparability of these two groups. The sample size in the control group $=374$ couples. Therefore, the total sample size was 561 couples[15]

\section{Sampling technique}

The multi-stage sampling technique was used to obtain the required sample size[17].

\section{Data collection}

Semi-structured questionnaires developed using Theory of Planned behavior was used for data collection[17].

\section{Data collection tools}

A semi-structured questionnaire had questions on the predictors of intention and intention. They were developed using the Theory of Planned Behavior [20]. 


\section{Variables}

\section{Dependent variables}

Domains of birth preparedness intention; attitudes, perceived subjective norms and perceived behavior control (figure 1)

\section{Independent variables}

Independent variables were the community-based continuous training project (figure 1)

\section{The Intervention (Community Based Continuous Training (CBCT) Project)}

This intervention was grounded in the Theory of Planned Behavior. The Community Based Continuous Training (CBCT) project aimed to improve birth preparedness, male involvement and maternal services utilization among expecting couples.

The project involved discussions about behavior beliefs, normative beliefs and behavior control beliefs, which hindered the health facility birth preparedness, male involvement and maternal services utilization. In addition to that, the project involved teaching about birth preparedness (antenatal services, danger signs and preparations for health facility birth), signs of labor and newborn care[15].

\section{Data analysis procedures}

Data were checked for completeness and consistency; then were coded and entered in to computer by using statistical package IBM SPSS version 23. Descriptive statistics were used to generate frequency distribution and cross tabulation was used to describe the characteristics of the study participants. The comparisons between groups were determined by using independent t-test and comparisons within groups (pre/post) were estimated using paired t-test. Factor analysis was used to extract the statements used to measure the domains of birth preparedness intentions (Table 1)

Table 1

Analysis procedure 
To determine the effectiveness of CBCT on improving domains of birth preparedness intention among expecting couples.

\begin{tabular}{llll}
$\begin{array}{l}\text { Initial } \\
\text { questions } \\
\text { analyzed }\end{array}$ & 19 & 25 & 24 \\
\hline $\begin{array}{l}\text { Initial Eigen } \\
\text { values (before } \\
\text { extraction) }\end{array}$ & $\begin{array}{l}\text { Comp } \\
1=37.245 \% ; \\
\text { Comp. } \\
2=13.905 \%\end{array}$ & $\begin{array}{l}\text { Comp.1=36.14\%; } \\
\text { Comp. }\end{array}$ & $\begin{array}{l}\text { Comp. } \\
1=43.428 \% ; \\
\text { Comp. }\end{array}$ \\
$2=17.420 \%$
\end{tabular}

Positive $=$ mean or above and negative below mean

\section{Results}

\section{Socio demographic characteristics}

The mean age of pregnant women in the intervention group was $25.6 \pm 6.899$ and in the control group was $25.55 \pm 6.775$. Ranging from 14 years to $49 y e a r s$. The mean age of their male partners in the intervention group was $30.09 \pm 7.743$ and in the control group was $30.93 \pm 7.714$. The age ranging from 18 to 54 years. Majority of pregnant women in intervention group (58.3\%) and control group (59.6) were younger than 25 years while majority of male respondents in intervention group $(65.9 \%)$ and in the control group (70.4\%) were older than 25 years. More than $70 \%$ of pregnant women in both groups were married at younger age of less than 18 years. Majority of the cohort had at least primary education. Majority of them were of low socio-economic status (earned less than 1 dollar per day), get basic obstetric care services from dispensaries, not covered by health insurance, and walking distance to a nearby health facility were less than five kilometers (Table 2). 
Table 2

Socio-demographic characteristics of respondents $(\mathrm{N}=1092)$

\begin{tabular}{|c|c|c|c|c|}
\hline \multirow[t]{2}{*}{ Character } & \multicolumn{2}{|c|}{ Intervention Group $\left(n_{1}=364\right)$} & \multicolumn{2}{|c|}{ Control group $\left(n_{2}=728\right)$} \\
\hline & Female $\left(n_{1}, \%\right)$ & Male $\left(n_{1}, \%\right)$ & Female $\left(n_{1}, \%\right)$ & Male $\left(n_{1}, \%\right)$ \\
\hline \multicolumn{5}{|l|}{ Age (years) } \\
\hline 14 to 19 years & $54(29.7)$ & $13(7.1)$ & 113(31) & $14(3.8)$ \\
\hline 20 to 25 & $52(28.6)$ & 49(26.9) & 104(28.6) & $94(25.8)$ \\
\hline 26 to 30 & $39(21.4)$ & $39(21.4)$ & $66(18.1)$ & 107(29.4) \\
\hline 31 to 35 & $15(8.2)$ & $38(20.9)$ & $40(11)$ & $49(13.5)$ \\
\hline 36 and above & $22(12.1)$ & $43(23.6)$ & $41(11.3)$ & $100(27.5)$ \\
\hline \multicolumn{5}{|l|}{ Age at Marriage (years) } \\
\hline Less than 18 & $130(71.4)$ & $26(14.3)$ & $265(72.8)$ & $45(12.4)$ \\
\hline 18 to 24 & $49(26.9)$ & 111(61) & $98(26.9)$ & $242(66.5)$ \\
\hline 25 and above & $3(1.6)$ & $45(24.7)$ & $1(0.3)$ & $77(21.2)$ \\
\hline \multicolumn{5}{|l|}{ Marital status } \\
\hline Cohabit & $45(24.7)$ & $44(24.2)$ & $111(30.5)$ & $110(30.2)$ \\
\hline Married & $137(75.3)$ & $138(75.8)$ & $253(69.5)$ & 254(69.8) \\
\hline \multicolumn{5}{|l|}{ Number of wives } \\
\hline Monogamous & $170(93.4)$ & $170(93.4)$ & $299(82.1)$ & $297(81.6)$ \\
\hline Polygamous & $12(6.6)$ & $12(6.6)$ & $65(17.9)$ & $67(18.4)$ \\
\hline \multicolumn{5}{|l|}{ Education level } \\
\hline Non-formal & $70(38.5)$ & $50(27.5)$ & $160(44)$ & $105(28.8)$ \\
\hline Primary School & $107(58.8)$ & $119(65.4)$ & 192(52.7) & $234(64.3)$ \\
\hline Secondary school or Higher & $5(2.7)$ & $13(7.1)$ & $12(3.3)$ & $25(6.9)$ \\
\hline \multicolumn{5}{|l|}{ Income per day } \\
\hline Less than 1 dollar & $119(65.4)$ & $118(64.8)$ & $280(76.9)$ & $264(72.5)$ \\
\hline More than 1 dollar & $63(34.6)$ & $64(35.2)$ & $84(23.1)$ & $100(27.5)$ \\
\hline \multicolumn{5}{|l|}{ Adult female in the family } \\
\hline None & 104(57.1) & 104(57.1) & $214(58.8)$ & $214(58.8)$ \\
\hline
\end{tabular}




\begin{tabular}{|c|c|c|c|c|}
\hline \multirow{2}{*}{$\begin{array}{l}\text { Character } \\
1 \text { or more }\end{array}$} & \multicolumn{2}{|c|}{ Intervention Group $\left(n_{1}=364\right)$} & \multicolumn{2}{|c|}{ Control group $\left(n_{2}=728\right)$} \\
\hline & $79(42.9)$ & $79(42.9)$ & $150(41.2)$ & $150(41.2)$ \\
\hline \multicolumn{5}{|l|}{ Ethnic group } \\
\hline Fipa & $155(27.6)$ & 175(31.2) & 178(31.7) & $203(36.2)$ \\
\hline Mambwe & $5(0.9)$ & $3(0.5)$ & $119(21.2)$ & $117(20.9)$ \\
\hline Others & $27(4.8)$ & $9(1.6)$ & 77(13.7) & $54(9.6)$ \\
\hline \multicolumn{5}{|c|}{ Health Insurance } \\
\hline Yes & $41(7.3)$ & $41(7.3)$ & $143(25.5)$ & $133(23.7)$ \\
\hline No & $146(26)$ & $146(26)$ & $231(41.2)$ & $241(43)$ \\
\hline \multicolumn{5}{|l|}{ Health facility } \\
\hline Dispensary & $141(25.1)$ & $141(25.1)$ & $325(57.9)$ & $325(57.9)$ \\
\hline Health center & $46(8.2)$ & $46(8.2)$ & $49(8.7)$ & $49(8.7)$ \\
\hline \multicolumn{5}{|c|}{ Distance to health facility } \\
\hline Less than 1 & $74(13.2)$ & 74 (13.2) & $188(33.5)$ & $188(33.5)$ \\
\hline 1 to 5 & $102(18.2)$ & 102(18.2) & $141(25.1)$ & $141(25.1)$ \\
\hline More than 5 & $11(2)$ & $11(2)$ & $45(8)$ & 45(8) \\
\hline \multicolumn{5}{|c|}{ Own mobile phone } \\
\hline Yes & $16(2.9)$ & $325(57.9)$ & $53(9.4)$ & 218(38.9) \\
\hline No & $171(30.5)$ & $49(8.7)$ & $321(57.2)$ & $156(27.8)$ \\
\hline
\end{tabular}

\section{Obstetric characteristics of pregnant women}

Majority of pregnant women (78.8\%) were multiparous. Eleven (1\%) multiparous women in the intervention group and $19(1.7 \%)$ in the control group had ever had a preterm delivery and only 2 women $(1.1 \%)$ in the intervention group and 11 women $(3 \%)$ in the control had ever had a previous cesarean section (Table 3 ). 
Table 3

Obstetric history of the female respondents

\begin{tabular}{|c|c|c|c|}
\hline Variable & $\begin{array}{l}\text { Intervention Group ( } \mathrm{n} 1, \%) \\
\mathrm{n}=187\end{array}$ & $\begin{array}{l}\text { Control group }(n 2, \%) \\
n=374\end{array}$ & $\begin{array}{l}\text { Total }(\mathrm{n} 1+\mathrm{n} 2) \\
\mathrm{n}=561\end{array}$ \\
\hline \multicolumn{4}{|c|}{ Gestation Age (Weeks) } \\
\hline$\leq 16$ & $29(5.17)$ & $90(16.04)$ & $119(21.2)$ \\
\hline $17-24$ & 158(28.16) & $284(50.62)$ & 442(78.8) \\
\hline \multicolumn{4}{|l|}{ Gravidity } \\
\hline Prime-gravid & $40(7.13)$ & $82(14.62)$ & 122(21.75) \\
\hline Multiparous & $147(26.2)$ & 292(52.05) & 439(78.3) \\
\hline \multicolumn{4}{|l|}{ Parity } \\
\hline Null-parous & $40(7.13)$ & $82(14.62)$ & 122(21.75) \\
\hline Para 1-4 & 109(19.43) & 221(39.39) & $330(58.82)$ \\
\hline Para 5+ & $38(6.77)$ & $71(12.66)$ & 109(19.43) \\
\hline \multicolumn{4}{|c|}{$\begin{array}{l}\text { History of pre-term } \\
\text { delivery }\end{array}$} \\
\hline Yes & $11(1.96)$ & 19(3.38) & $30(5.35)$ \\
\hline No & 176(31.37) & $355(63.28)$ & $531(94.65)$ \\
\hline \multicolumn{4}{|c|}{$\begin{array}{l}\text { History of Caesarean } \\
\text { section }\end{array}$} \\
\hline Yes & $3(0.5)$ & $11(1.96)$ & $14(2.49)$ \\
\hline No & 184(32.79) & $363(64.71)$ & $547(97.5)$ \\
\hline
\end{tabular}

\section{Domains of birth preparedness Intention (Attitudes, Subjective norms and Perceived behavior control)}

Descriptive characteristics of attitudes, subjective norms and perceived behavior control towards birth preparedness. Among both pregnant women and their male partners all three domains were slightly higher among control group if compared to intervention group. At post-test all three domains were slightly higher in the intervention group as compared to control group (figure 2 and 3 and Table 4). 
Table 4

Descriptive characteristics of the domains of birth preparedness intention

\begin{tabular}{|c|c|c|c|c|c|c|c|c|c|}
\hline & \multicolumn{5}{|c|}{ Baseline assessment } & \multicolumn{4}{|c|}{ End-line assessment } \\
\hline & & \multicolumn{2}{|c|}{ Intervention } & \multicolumn{2}{|c|}{ Control } & \multicolumn{2}{|c|}{ Intervention } & \multicolumn{2}{|c|}{ Control } \\
\hline & & Freq & $\%$ & Freq & $\%$ & Freq & $\%$ & Freq & $\%$ \\
\hline & \multicolumn{9}{|c|}{ Attitude towards BP } \\
\hline & Negative & 116 & 63.7 & 205 & 56.3 & 81 & 44.5 & 193 & 53 \\
\hline & Positive & 66 & 36.3 & 159 & 43.7 & 101 & 55.5 & 171 & 47 \\
\hline & \multicolumn{9}{|c|}{ Subjective norms } \\
\hline \multirow[t]{6}{*}{ Pregnant women } & Negative & 122 & 67 & 213 & 58.5 & 91 & 50 & 224 & 61.5 \\
\hline & Positive & 60 & 33 & 151 & 41.5 & 91 & 50 & 140 & 38.5 \\
\hline & \multicolumn{9}{|c|}{ Perceived behavior control } \\
\hline & Negative & 113 & 62.1 & 205 & 56.3 & 91 & 50 & 193 & 53 \\
\hline & Positive & 69 & 37.9 & 159 & 43.7 & 91 & 50 & 171 & 47 \\
\hline & \multicolumn{9}{|c|}{ Attitude towards BP } \\
\hline \multirow[t]{8}{*}{ Male partners } & Negative & 115 & 63.5 & 207 & 56.7 & 78 & 43.1 & 169 & 46.3 \\
\hline & Positive & 66 & 36.5 & 158 & 43.3 & 103 & 56.9 & 196 & 53.7 \\
\hline & \multicolumn{9}{|c|}{ Subjective norms } \\
\hline & Negative & 122 & 67.4 & 216 & 59.2 & 95 & 52.5 & 188 & 51.5 \\
\hline & Positive & 59 & 32.6 & 149 & 40.8 & 86 & 47.5 & 177 & 48.5 \\
\hline & \multicolumn{9}{|c|}{ Perceived behavior control } \\
\hline & Negative & 121 & 66.9 & 206 & 56.4 & 98 & 54.1 & 168 & 46.0 \\
\hline & Positive & 60 & 33.1 & 159 & 43.6 & 83 & 45.9 & 197 & 54.0 \\
\hline
\end{tabular}

\section{The effectiveness of CBCT on improving domains of birth preparedness intention among expecting couples.}

\section{a. Comparison between group both at baseline and end-line on birth preparedness}


An independent t- test was performed to compare attitudinal mean score, subjective norms means score and perceived behavior mean score at baseline assessment and end-line assessment among both pregnant women and male spouses. At end-line assessment subjective norms towards birth preparedness revealed a significant mean score differences between the intervention group and control group among pregnant women $(p<0.05)$ (Table 5)

Table 5

Comparison between groups domains of birth preparedness intention

\begin{tabular}{|c|c|c|c|c|c|}
\hline \multirow{2}{*}{ Variables } & \multirow[t]{2}{*}{ t-test } & \multirow{2}{*}{$\begin{array}{l}\text { mean } \\
\text { difference }\end{array}$} & \multicolumn{3}{|l|}{$95 \% \mathrm{Cl}$} \\
\hline & & & Lower & Upper & P-value \\
\hline \multicolumn{6}{|l|}{ Attitude } \\
\hline Male baseline & -1.554 & -0.069 & -0.156 & 0.018 & 0.121 \\
\hline Male end-line & 0.608 & 0.027 & -0.061 & 0.116 & 0.544 \\
\hline Female baseline & -1.55 & -0.069 & -0.156 & 0.018 & 0.122 \\
\hline Female end-line & 1.881 & 0.085 & -0.004 & 0.174 & 0.061 \\
\hline \multicolumn{6}{|l|}{ Subjective norms } \\
\hline Male baseline & -1.903 & -0.082 & -0.168 & 0.003 & 0.058 \\
\hline Male end-line & -0.302 & -0.014 & 0.763 & -0.103 & 0.076 \\
\hline Female baseline & -1.828 & -0.08 & -0.165 & 0.006 & 0.068 \\
\hline Female end-line & 2.559 & 0.115 & 0.027 & 0.204 & 0.011 \\
\hline \multicolumn{6}{|c|}{ Perceived behavior control } \\
\hline Male baseline & -2.396 & -0.104 & -0.19 & -0.019 & 0.017 \\
\hline Male end-line & -1.879 & -0.085 & -0.174 & 0.004 & 0.061 \\
\hline Female baseline & -1.171 & -0.052 & -0.14 & 0.035 & 0.242 \\
\hline Female end-line & 0.665 & 0.030 & -0.059 & 0.120 & 0.507 \\
\hline
\end{tabular}

\section{b. Comparison within the groups- domains of birth preparedness intention}

The mean attitudinal score deference within groups were significant in both intervention $(p<0.001)$ and control groups (0.01) among male respondent. The difference was significant only in the intervention $(p<0.001)$ among pregnant women. In subjective norms, the mean score difference was significant in both intervention group $(p<0.01)$ and control group $(p<0.05)$ among male respondents. The mean score 
difference was significant only in intervention group $(p<0.01)$ among pregnant women. In perceived behavior control the mean score difference was significant both in intervention group $(p<0.05)$ and control group $(p<0.01)$ among male respondents while among pregnant women the significant difference was only in intervention group $(p<0.05)$ Table 6.

Table 6

Comparison within the groups- domains of birth preparedness intention

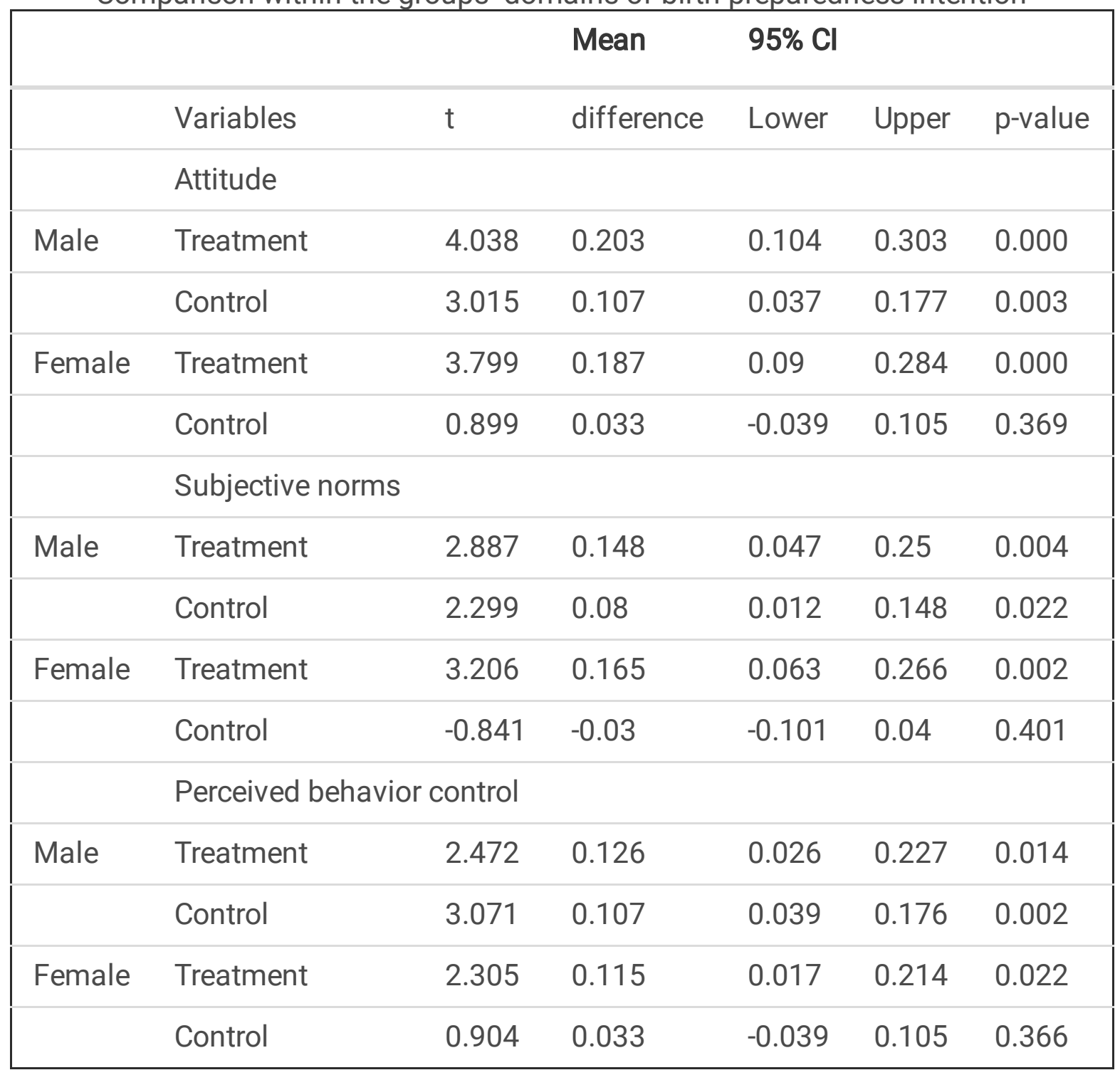

\section{c. Predictors of change in attitude, subjective norms and perceived behavior control towards birth preparedness.}

The predictor of change on attitudes towards birth preparedness was only the intervention $\beta=0.065$, $p<0.05$. Predictor of change on subjective norms towards birth preparedness was as well the intervention $\beta=0.112, p=0.001$. Predictors of change in perceived behavior control towards birth preparedness were level of education (secondary school, $\beta=0.066, p<0.05$ ), age at marriage (more than 24 years, $\beta=0.069$, $p<0.05$ ) and ethnic group (others, $\beta=-0.067, p<0.05$ ) Table 7. 
Table 7

Predictors of change in the domains of birth preparedness intentions

$95.0 \% \mathrm{Cl}$

\begin{tabular}{|c|c|c|c|c|c|c|c|}
\hline & Variables & B & Beta & $\mathrm{t}$ & Lower & Upper & $\begin{array}{l}p- \\
\text { value }\end{array}$ \\
\hline \multirow[t]{8}{*}{ Attitude } & (Constant) & -0.291 & & -2.304 & -0.539 & -0.043 & 0.021 \\
\hline & Age at marriage (19-24) & 0.111 & 0.04 & 1.231 & -0.066 & 0.288 & 0.219 \\
\hline & Age at marriage $(25+)$ & 0.244 & 0.056 & 1.734 & -0.032 & 0.52 & 0.083 \\
\hline & $\begin{array}{l}\text { Ethnic group } \\
\text { (Mambwe) }\end{array}$ & 0.087 & 0.026 & 0.766 & -0.136 & 0.311 & 0.444 \\
\hline & Ethnic group (Others) & -0.209 & -0.053 & -1.665 & -0.454 & 0.037 & 0.096 \\
\hline & $\begin{array}{l}\text { Economic status (At } \\
\text { least one) }\end{array}$ & 0.019 & 0.006 & 0.205 & -0.167 & 0.206 & 0.838 \\
\hline & Intervention group & 0.194 & 0.065 & 1.98 & 0.002 & 0.387 & 0.048 \\
\hline & $\begin{array}{l}\text { Ever heard about birth } \\
\text { preparedness }\end{array}$ & -0.032 & -0.009 & -0.288 & -0.252 & 0.187 & 0.774 \\
\hline \multirow{5}{*}{$\begin{array}{l}\text { Subjective } \\
\text { norms }\end{array}$} & (Constant) & -0.315 & & -4.592 & -0.45 & -0.18 & 0 \\
\hline & $\begin{array}{l}\text { Ethnic group } \\
\text { (Mambwe) }\end{array}$ & 0.027 & 0.008 & 0.254 & -0.183 & 0.238 & 0.799 \\
\hline & Ethnic group (Others) & 0.005 & 0.001 & 0.042 & -0.227 & 0.237 & 0.966 \\
\hline & $\begin{array}{l}\text { Economic status (At } \\
\text { least one) }\end{array}$ & -0.09 & -0.031 & -1.003 & -0.267 & 0.086 & 0.316 \\
\hline & Intervention group & 0.315 & 0.112 & 3.393 & 0.133 & 0.496 & 0.001 \\
\hline \multirow{7}{*}{$\begin{array}{l}\text { Perceived } \\
\text { behavior control }\end{array}$} & (Constant) & -0.179 & & -1.364 & -0.438 & 0.079 & 0.173 \\
\hline & $\begin{array}{l}\text { Ethnic group } \\
\text { (Mambwe) }\end{array}$ & 0 & 0 & 0.002 & -0.221 & 0.221 & 0.999 \\
\hline & Ethnic group (Others) & -0.262 & -0.067 & -2.111 & -0.505 & -0.018 & 0.035 \\
\hline & Intervention group & 0.144 & 0.049 & 1.498 & -0.045 & 0.333 & 0.134 \\
\hline & $\begin{array}{l}\text { Education level } \\
\text { (Primary School) }\end{array}$ & -0.106 & -0.038 & -1.175 & -0.284 & 0.071 & 0.24 \\
\hline & $\begin{array}{l}\text { Education level } \\
\text { (Secondary school) }\end{array}$ & 0.421 & 0.066 & 2.077 & 0.023 & 0.818 & 0.038 \\
\hline & Age at marriage (19-24) & 0.053 & 0.019 & 0.59 & -0.124 & 0.23 & 0.555 \\
\hline
\end{tabular}




\begin{tabular}{|llllllll|}
\hline & & \multicolumn{5}{c|}{$95.0 \%$ Cl } \\
\hline & 0.301 & 0.069 & 2.137 & 0.025 & 0.578 & 0.033 \\
\hline $\begin{array}{l}\text { Age at marriage (25+) } \\
\text { Ever heard about birth } \\
\text { preparedness }\end{array}$ & 0.03 & 0.008 & 0.268 & -0.188 & 0.247 & 0.789 \\
\hline
\end{tabular}

\section{Discussion}

Majority of study respondents in both intervention and control groups had negative attitudes towards birth preparedness at baseline assessment. This finding could be due to low risk perception towards pregnancy and childbirth. A previous study done in the same setting has reported that parents perceive pregnancy and childbirth as a natural normal process which is not associated with risks[4]. The low risk perception was largely contributed by low knowledge on obstetric danger signs[14]. The negative attitude towards health facility birth influence the intention to engage into the behavior and hence the occurrence of the behavior[16]. Different finding was reported by a previous study that majority of interviewed respondents had positive attitudes towards birth preparedness[21]. The difference could be due to differences in study population, the study interviewed pregnant women attending antenatal while this study interviewed pregnant women and their male partners in the community. Sampling pregnant women who are attending antenatal clinic could have included those who perceive pregnancy and childbirth are associated with risks.

The perceived subjective norms domain was also low among both pregnant women and their male partners at baseline assessment. Majority of interviewed women perceived that the behavior towards birth preparedness is not approved by important others. This could be due to cultural practice which influenced the acceptability of birth preparedness[22]. In the community the study was carried on, majority of pregnant women used traditional birth attendants. The cost of childbirth is relatively chip and sometimes paid in kind. The persistent use of traditional birth attendants could have influenced the perceived subjective norms in the sense that a traditional birth attendant who is sometimes your mother in law may be perceived to disapprove the health facility birth preparedness.

The study also revealed that the perceived behavior control was low among the respondents at baseline assessment. Majority of them perceive they are not able to prepare for health facility birth. This can be contributed to the low socio-economic status of the study community. The low risk perception stimulates the low priority setting in allocating resources for birth preparedness.

In comparison between groups at posttest assessment, there was a significant increase in mean scores only on perceived subjective norms in the intervention group if compared to the control group among pregnant women. This means CBCT project is effective in improving pregnant women perceived subjective norms. Among male partners, none of the domain showed a significant difference between the 
intervention group and control group. All three domains showed an increase in mean score in the intervention group when compared with control group but the increase was not statistically significant. The increase in mean score in the intervention group provides an indicator that the CBCT project has the potential in changing these domains. The lack of significant change in the intervention group could be due to the dosage of the intervention and the time allowed for posttest assessment. The study recommends a future project which will add the dosage and duration of posttest assessment.

When the comparison was done within the group, mean scores in all three domains had significant increase at posttest in both groups among male partners while among pregnant women the significant increase in the three domains were only among intervention group. Significant increase in mean scores of all three domains among male partners was a surprising finding. The possible reason could be due to the effect of change in time.

Predictors of change in attitudes mean scores and perceived subjective norms mean scores were only the CBCT project. This means that the $\mathrm{CBCT}$ project has the ability to improve attitude and perceived subjective norms. The author recommends the use of $\mathrm{CBCT}$ intervention to improve the two domains (attitude and perceived behavior control) of birth preparedness intention.

The predictors of change of perceived behavior control mean scores were level of education, age at marriage and ethnic group. The CBCT project had no effect on the change perceived behavior control mean scores. This could be the behavior itself to occur requires the availability of resources. Their perception towards the ability to execute the behavior is influenced by the low socio-economic status. The CBCT project alone could not change their beliefs about their ability to prepare for birth and unanticipated emergencies. The study recommends for another community-based intervention to work out an innovative strategy to improve socio-economic status of expecting couples.

The improvement brought by the intervention indicates that the intervention has the potential to significantly change the attitude and subjective norms domains of BPCR intention. The study recommends the $\mathrm{CBCT}$ intervention to be used in rural community to improve attitude and perceived subjective norms of BPCR intention.

\section{Conclusion}

The improvement brought by the intervention indicates that the intervention has the potential to significantly change the attitude and subjective norms domains of BPCR intention. The study recommends the CBCT intervention to be used in rural community to improve attitude and perceived subjective norms of BPCR intention.

\section{Abbreviations}


CBCT Community Based Continuous Training

\section{Declarations}

\section{Ethics approval and consent to participate}

Approval to conduct the study was given by the University of Dodoma Research and Publication Committee. Government authorities at regional and council levels ( Sumbawanga and Kalambo) were contacted for permission to conduct the study. Both written and oral informed consent was obtained from the study participants. For pregnant women who were younger than 18years, a consent to participate to the study was sought from their husbands. All methods were carried out in accordance with relevant guidelines and regulations.

\section{Acknowledgments}

The author thanks the University of Dodoma for providing ethical clearance for this study. I am also grateful to the administration of Rukwa Region for allowing us to conduct the study and to each of the study participants for their participation in this study.

\section{Competing interests}

Author declares that there is no competing interest.

\section{Funding}

The study was not funded.

\section{Authors' contributions}

Fabiola Moshi did the conception, design, acquisition of data, analysis, interpretation of data, and write the manuscript.

\section{Consent for publication}

Not applicable 


\section{Availability of data and materials}

Data set is available and can be shared on request from fabiola.moshi@gmail.com

\section{References}

1. Acharya, A. S., Kaur, R., Prasuna, J. G., \& Rasheed, N. (2015). Making Pregnancy Safer - Birth Preparedness and Complication Readiness Study among Antenatal Women Attendees of A Primary Health Center, Delhi. In Indian Journal of Community Medicine (Vol. 40, Issue 2, pp. 127-134). https://doi.org/10.4103/0970-0218.153881

2. Thaddeus, S., \& Maine, D. (1994). Too far to walk: Maternal mortality in context. In Social Science and Medicine (Vol. 38, Issue 8, pp. 1091-1110). https://doi.org/10.1016/0277-9536(94)90226-7

3. Moshi, F. V., Ernest, A., Fabian, F., \& Kibusi, S. M. (2018). Knowledge on birth preparedness and complication readiness among expecting couples in rural Tanzania: Differences by sex crosssectional study. PLOS ONE, 13(12). https://doi.org/10.1371/journal.pone.0209070

4. Moshi, F., \& Nyamhanga, T. (2017). Understanding the preference for homebirth; an exploration of key barriers to facility delivery in rural Tanzania. Reproductive Health, 14(1), 132. https://doi.org/10.1186/s12978-017-0397-z

5. A., G., C., C., A., M., \& D., L. (2018). Barriers to access and utilization of emergency obstetric care at health facilities in sub-Saharan Africa-a systematic review protocol. Systematic Reviews, 7(1), 1-14. http://www.embase.com/search/results? subaction=viewrecord\&from=export\&id=L621667553\%0Ahttp://dx.doi.org/10.1186/s13643-0180720-y

6. Jhpiego. (2004). Monitoring birth preparedness and complication readiness: tools and indicators for maternal and newborn health. 1-338. http://pdf.usaid.gov/pdf_docs/PNADA619.pdf

7. Soubeiga, D., Gauvin, L., Hatem, M.A. and Johri, M. (2014). Birth Preparedness and Complication Readiness (BPCR) interventions to reduce maternal and neonatal mortality in developing countries: Systematic review and meta-analysis. BMC Pregnancy and Childbirth, 14(1), no pagination. https://doi.org/10.1186/1471-2393-14-129

8. Bintabara, D., Mohamed, M. A., Mghamba, J., Wasswa, P., \& Mpembeni, R. N. M. (2015). Birth preparedness and complication readiness among recently delivered women in chamwino district, central Tanzania: a cross sectional study. Reproductive Health, 12(1), 44. https://doi.org/10.1186/s12978-015-0041-8

9. Hailu, M., Gebremariam, A., Alemseged, F., \& Deribe, K. (2011). Birth preparedness and complication readiness among pregnant women in Southern Ethiopia. PLOS ONE, 6(6). https://doi.org/10.1371/journal.pone.0021432

10. Urassa, D. P., Pembe, A. B., \& Mganga, F. (2012). Birth preparedness and complication readiness among women in Mpwapwa district, Tanzania. Tanzania Journal of Health Research, 14(1), 1-7. https://doi.org/10.4314/thrb.v14i1.8 
11. Sodeinde, K. J., Amoran, O. E., \& Abiodun, O. A. (2020). Male involvement in birth preparedness in Ogun State, Nigeria: A rural/urban comparative cross-sectional study. African Journal of Reproductive Health, 24(2), 70-84. https://doi.org/10.29063/ajrh2020/v24i2.7

12. Lewis, S., Lee, A., \& Simkhada, P. (2015). The role of husbands in maternal health and safe childbirth in rural Nepal: A qualitative study. BMC Pregnancy and Childbirth, 15(1), 1-10. https://doi.org/10.1186/s12884-015-0599-8

13. Maluka, S. O., \& Peneza, A. K. (2018). Perceptions on male involvement in pregnancy and childbirth in Masasi District, Tanzania: A qualitative study. Reproductive Health, 15(1), 1-7. https://doi.org/10.1186/s12978-018-0512-9

14. Moshi, F. V., Ernest, A., Fabian, F., \& Kibusi, S. M. (2018). Knowledge on birth preparedness and complication readiness among expecting couples in rural Tanzania: Differences by sex crosssectional study. 1-15.

15. Moshi, F. V., Kibusi, S. M., \& Fabian, F. M. (2021). The impact of community based continuous training project on improving couples' knowledge on birth preparedness and complication readiness in rural setting Tanzania; A controlled quasi-experimental study. PLOS ONE, 16(1 January 2021). https://doi.org/10.1371/journal.pone.0244845

16. Netemeyer, R., Ryn, M. Van, \& Ajzen, I. (1991). The theory of planned behavior. Organizational Behavior and Human Decision Processes, 50(2), 179-211. https://doi.org/10.1016/07495978(91)90020-T

17. Moshi, F. V., Kibusi, S. M., \& Fabian, F. (2018). Using the Theory of Planned Behavior to Explain Expecting Couples Birth Preparedness Intentions in a Rural Setting: A Cross-Sectional Study from Rukwa, Southern Tanzania. Advances in Public Health, 2018, 1-9. https://doi.org/10.1155/2018/1087342

18. West, C. I. T., \& Briggs, N. C. T. (2015). Effectiveness of trained community volunteers in improving knowledge and management of childhood malaria in a rural area of Rivers State, Nigeria. 18(5).

19. National Bureau of Statistics. (2010). Tanzania Demographic and Health Survey (Issue April). http://www.measuredhs.com.

20. Ajzen, I., \& Fishbein, M. (2006). Constructing a theory of planned behavior questionnaire. Predicting and Changing Behavior: The Reasoned Action Approach, January, 1-7. https://doi.org/10.1016/0749-5978(91)90020-T

21. Ebere Ogonna, M. (2018). Knowledge, Attitude and Practice of Birth Preparedness and Complication Readiness Amongst Pregnant Women in Eti-osa Lga, Lagos. Universal Journal of Public Health, 6(4), 220-230. https://doi.org/10.13189/ujph.2018.060408

22. Choudhury, N., \& Ahmed, S. M. (2011). Maternal care practices among the ultra poor households in rural Bangladesh: A qualitative exploratory study. BMC Pregnancy and Childbirth, 11, 1-8. https://doi.org/10.1186/1471-2393-11-15

\section{Figures}




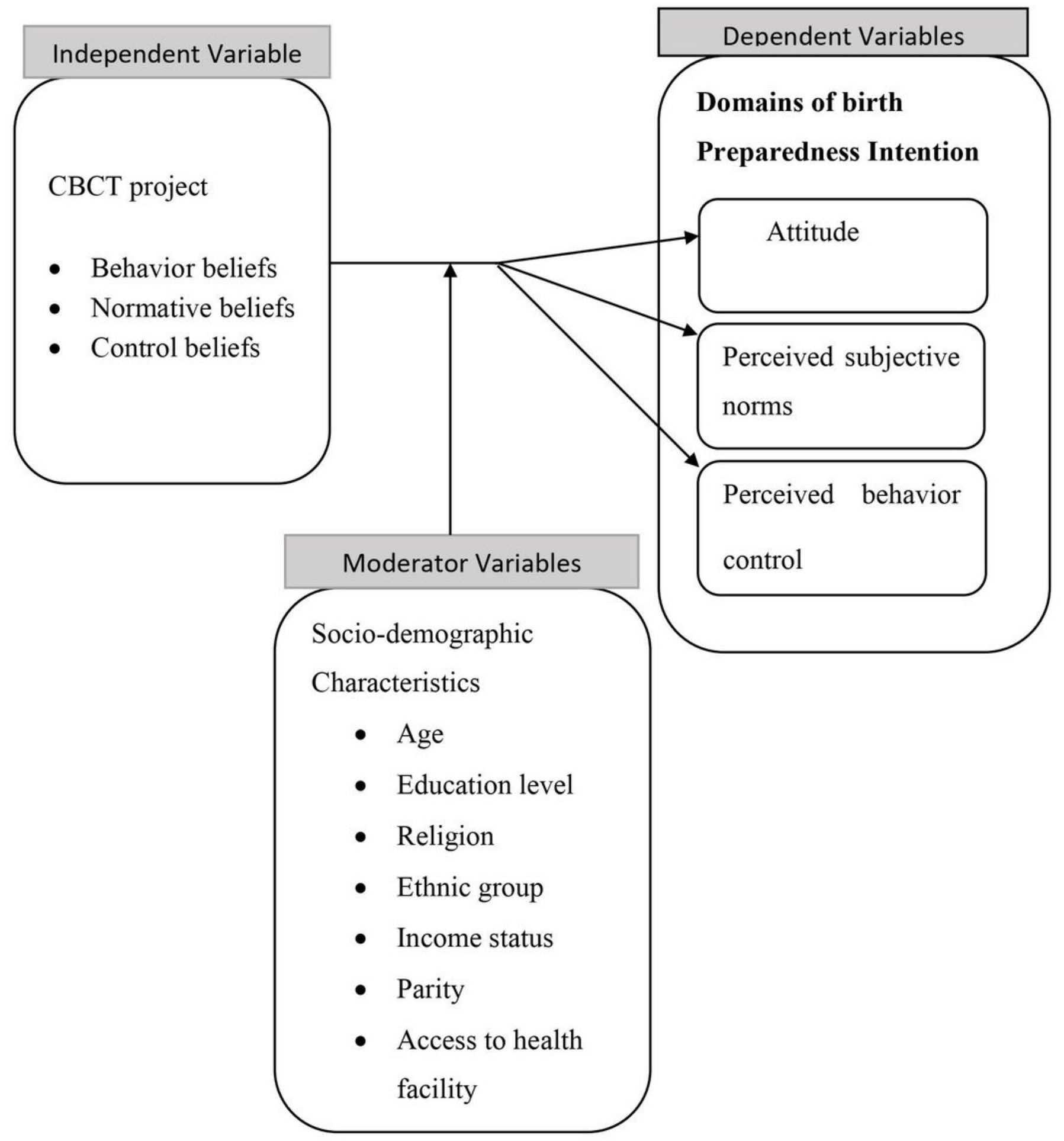

Figure 1

Study variables 


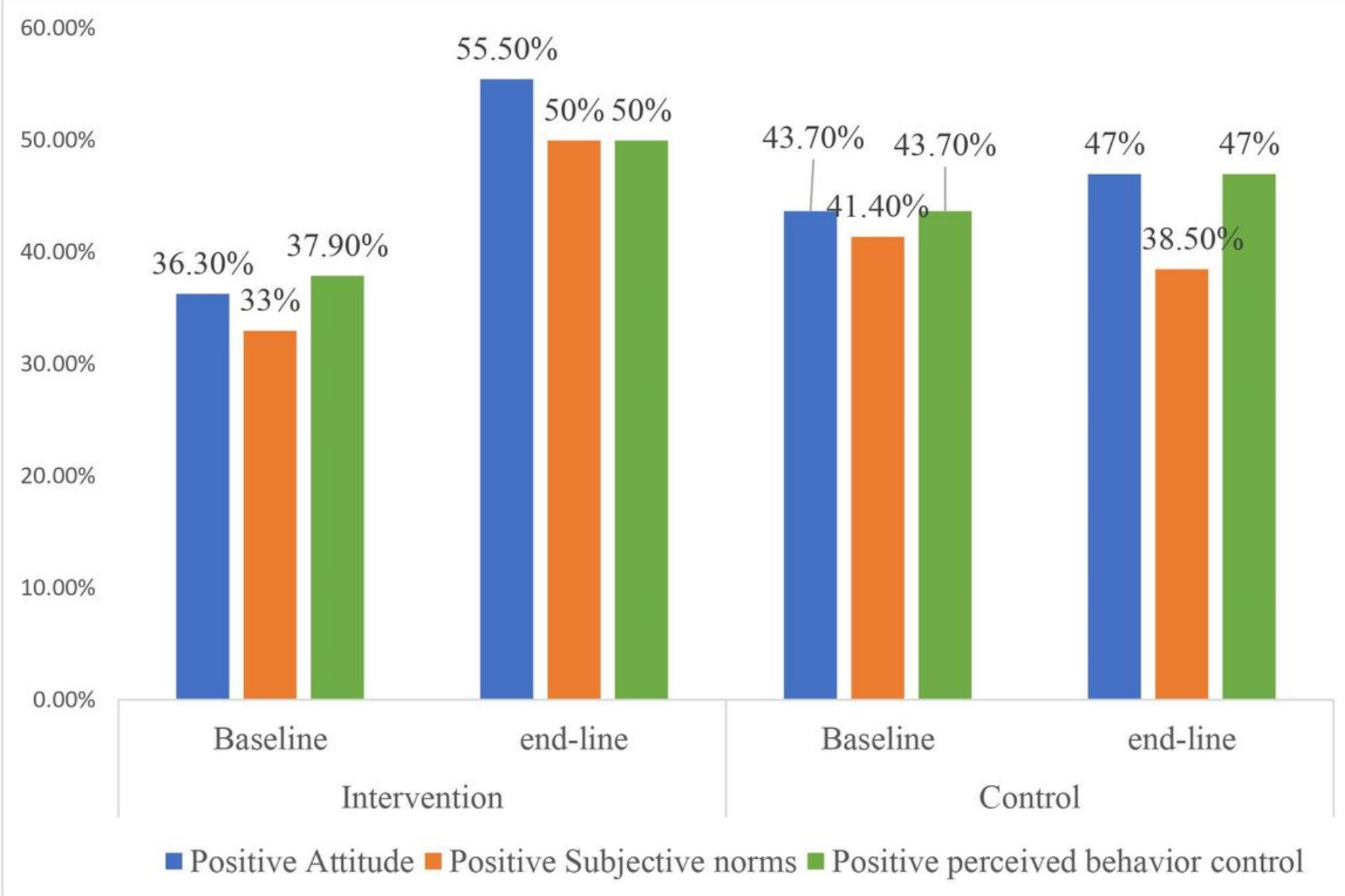

\section{Figure 2}

Domains of birth preparedness intention among pregnant women 


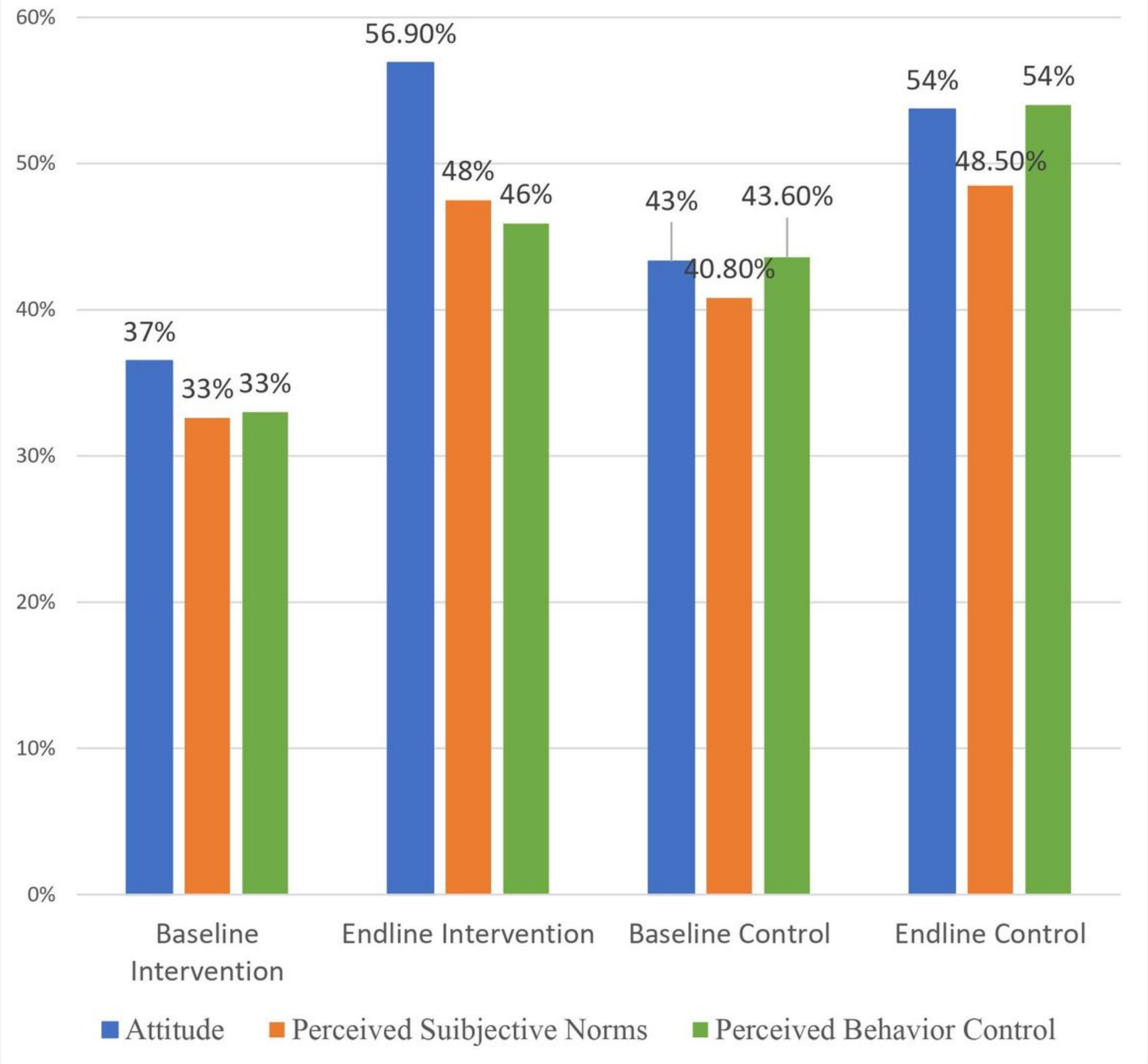

\section{Figure 3}

Domains of birth preparedness intention among male partners 